\title{
Ion-sculpting of Nanopores in Amorphous Metals, Semiconductors and Insulators
}

\section{Citation}

George, H. Bola, David P. Hoogerheide, Charbel S. Madi, David C. Bell, Jene A. Golovchenko, and Michael J. Aziz. 2010. Ion-sculpting of nanopores in amorphous metals, semiconductors and insulators. Applied Physics Letters 96, no.26: 263111.

\section{Published Version}

doi:10.1063/1.3441406

\section{Permanent link}

http://nrs.harvard.edu/urn-3:HUL.InstRepos:10345122

\section{Terms of Use}

This article was downloaded from Harvard University's DASH repository, and is made available under the terms and conditions applicable to Open Access Policy Articles, as set forth at http:// nrs.harvard.edu/urn-3:HUL.InstRepos:dash.current.terms-of-use\#OAP

\section{Share Your Story}

The Harvard community has made this article openly available.

Please share how this access benefits you. Submit a story.

Accessibility 


\title{
lon-sculpting of nanopores in amorphous metals, semiconductors and insulators
}

\author{
H. Bola George ${ }^{1}$, David P. Hoogerheide ${ }^{2}$, Charbel S. Madi ${ }^{1}$, David C. Bell ${ }^{1,3}$, Jene A. Golovchenko ${ }^{1,2}$ \\ and Michael J. Aziz ${ }^{1, *}$ \\ ${ }^{1}$ Harvard School of Engineering and Applied Sciences, Cambridge, Massachusetts 02138, USA \\ ${ }^{2}$ Department of Physics, Harvard University, Cambridge, Massachusetts 02138, USA \\ ${ }^{3}$ Center for Nanoscale Systems, Harvard University, Cambridge, Massachusetts 02138, USA \\ (Received ; accepted ; published )
}

We report the closure of nanopores to single-digit nanometer dimensions by ion sculpting in a range of amorphous materials including insulators $\left(\mathrm{SiO}_{2}\right.$ and $\left.\mathrm{SiN}\right)$, semiconductors (a-Si) and metallic glasses $\left(\mathrm{Pd}_{80} \mathrm{Si}_{20}\right)$ - the building blocks of a single-digit nanometer electronic device. Ion irradiation of nanopores in crystalline materials ( $\mathrm{Pt}$ and $\mathrm{Ag}$ ) does not cause nanopore closure. Ion irradiation of c-Si pores below $100{ }^{\circ} \mathrm{C}$ and above $600{ }^{\circ} \mathrm{C}$, straddling the amorphous-crystalline dynamic transition temperature, yields closure at the lower temperature but no mass transport at the higher temperature. Ion beam nano-sculpting appears to be restricted to materials that either are or become amorphous during ion irradiation. (C) 2010 American Institute of Physics. [doi: 10.1063/1.2905297]

The use of ion beams is an attractive method for the manipulation of solid morphologies with control possible at molecular dimensions. Examples include ion beam nanosculpting - the ion-induced reduction in nanopore diameter to single-digit nanometer dimensions - in insulators ${ }^{1}$, as well as nanoscale self-organized pattern formation ${ }^{2}$ in different materials classes: metals ${ }^{3}$, semiconductors ${ }^{4-8}$ and insulators ${ }^{9,10}$ with lateral length scales now reaching ${ }^{10} 7 \mathrm{~nm}$. Control of these three materials classes simultaneously at single-digit nanometer scales could enable broadly configurable, sub-lithographic device fabrication: for example, complex devices assembled from semiconductors, metals, and insulators with $\sim 100$-nm dimensions might be shrunk down to molecular dimensions by spatially uniform ion beam irradiation. The integration of nanopores into single biomolecule detecting devices has permitted the measurement of the folding conformations of individual biomolecules $^{11}$ and, ultimately, holds promise for rapid DNA sequencing.

In this Letter we report the use of ion beam nanosculpting to close individual nanopores to single-digit nanometer dimensions in the three materials classes used for the typical electronic device. The materials exhibiting nanopore closure are all amorphous: $a$-Si (semiconductor), $\mathrm{SiO}_{2}$ and $\mathrm{SiN}_{\mathrm{x}}$ (insulator), and $\mathrm{Pd}_{80} \mathrm{Si}_{20}$ (metallic glass) or rapidly become amorphous upon the initiation of ion irradiation $\left(c-\mathrm{Si}\right.$, held at temperature $\left.T<100^{\circ} \mathrm{C}\right)$. Our results showing that the sculpting effect is limited to amorphous materials are predicted by an irradiation-induced anisotropic deformation mechanism that occurs only in amorphous materials. ${ }^{12,13}$

Samples were prepared as follows, unless stated otherwise: (1) fabrication of $50 \mu \mathrm{m} \times 50 \mu \mathrm{m}$ free-standing membranes by a series of photolithography and wet etching steps, (2) milling of pores in the free-standing membranes using a $50 \mathrm{keV} \mathrm{Ga}^{2+}$ focused ion beam (FIB) machine, and (3) low energy argon irradiation.

For the nitride experiments, the samples used were 200-nm thick low-pressure chemical vapor deposition (LPCVD) grown non-stoichiometric $\mathrm{SiN}_{\mathrm{x}} / \mathrm{Si}(001)$ substrate.

For the oxide studies, the samples used were $200-\mathrm{nm}$ thick LPCVD-grown $\mathrm{SiN}_{\mathrm{x}} / 500$-nm thick thermally grown $\mathrm{SiO}_{2} / \mathrm{Si}(001)$. After fabrication of the membranes, the topmost 200-nm thick $\mathrm{SiN}_{\mathrm{x}}$ capping layer was dissolved in hot phosphoric acid to expose the oxide surface, prior to milling of the pores.

The free-standing oxide membranes were the starting point for the fabrication of the amorphous silicon $(a-\mathrm{Si})$, palladium silicide $\left(\mathrm{Pd}_{80} \mathrm{Si}_{20}\right)$, Pt and $\mathrm{Ag}$ samples. For $a-\mathrm{Si}$, we milled $\sim 700 \mathrm{~nm}$ diameter pores in oxide membranes prior to $a$-Si deposition. We subsequently deposited $\sim 250$ $\mathrm{nm} a$-Si at a rate of $0.025 \mathrm{~nm} \mathrm{~s}^{-1}$ using an RF magnetron sputter deposition chamber with a base pressure of $7.7 \times$ $10^{-7}$ torr. For the $\mathrm{Pd}_{80} \mathrm{Si}_{20}$ pores, we milled $\sim 350 \mathrm{~nm}$ diameter holes in the $\mathrm{SiO}_{2}$ membranes prior to deposition of $\sim 650 \mathrm{~nm}$ amorphous $\mathrm{Pd}_{80} \mathrm{Si}_{20}$ at $0.07 \mathrm{~nm} \mathrm{~s}^{-1}$ using an ion sputter deposition system with a base pressure of $8.3 \times 10^{-7}$ torr. FIB milling of pores in the oxide membranes prior to deposition of either $a-\mathrm{Si}$ or $\mathrm{Pd}_{80} \mathrm{Si}_{20}$ was undertaken to reduce potential of $\mathrm{Ga}$ contamination from the FIB milling step. For Pt and Ag, we deposited $120 \mathrm{~nm}$ and $350 \mathrm{~nm}$ on the oxide membranes using electron beam and thermal sources, respectively. In all cases involving deposition, no special precautions were taken to keep the samples cool during ambient temperature deposition.

For the experiments on crystalline silicon (c-Si), we employed $260 \mathrm{~nm} \mathrm{Si} / 1 \mu \mathrm{m} \mathrm{SiO} / 625 \mu \mathrm{m} \mathrm{Si}$ (SOI) substrates supplied by Silicon on Insulator Technologies. We deposited $\sim 300 \mathrm{~nm}$ of $\mathrm{SiN}_{\mathrm{x}}$ by LPCVD and subsequently patterned the samples using standard photolithography and employed wet etching steps to fabricate $50 \mu \mathrm{m} \times 50 \mu \mathrm{m}$ membranes. Again the topmost $\mathrm{SiN}_{\mathrm{x}}$ capping layer was dissolved by immersion in hot phosphoric acid prior to FIB milling of pores under the conditions described earlier.

The ion sculpting apparatus has been described in detail elsewhere, ${ }^{1,14}$ typical parameters included operation of the Kaufmann-source $\mathrm{Ar}^{+}$ion beam at $3 \mathrm{keV}$ in continuous mode at normal incidence, chamber base pressure less than $10^{-7}$ torr, and differentially-pumped argon flowing into the chamber at $2.0 \times 10^{-6}$ mbar. Feedback-controlled counting of the $\mathrm{Ar}^{+}$ions going through the pore in real-time, and knowledge of the initial pore size from transmission electron microscopy (TEM), allow the determination of the pore area in real time as it evolves during ion sculpting. Temperature control is achieved to within $1^{\circ} \mathrm{C}$ using liquid nitrogen refrigeration and a local resistive heater.

TEM imaging and diffraction of PdSi nanopores were performed in a JEOL 100CX2 TEM operating at $60 \mathrm{kV}$ and a field emission JEOL 2010 TEM operating at $200 \mathrm{kV}$, 
respectively. For the a-Si nanopores, to prevent hydrocarbon surface contamination from accumulating in the pores during TEM imaging and being confused with closure by the accretion of silicon, special precautions were required. We kept the pre-(post)-ion-irradiated c-Si nanopores in a clean nitrogen environment and exposed them to the atmosphere only for as long as it took for them to be transferred to the irradiation chamber (TEM). TEM imaging and diffraction of the a-Si nanopores were performed using a JEOL 2100 TEM operating in a vacuum of $4.5 \times 10^{-6} \mathrm{mbar}$ at a reduced voltage of $120 \mathrm{kV}$ to remain below the radiation damage threshold for silicon ${ }^{15}$, nominally $145 \mathrm{keV}$ and presumed to be somewhat lower for a-Si.

Typical results for pore area vs. fluence during ion sculpting are shown in Fig. 1a. TEM micrographs of a $\mathrm{Pd}_{80} \mathrm{Si}_{20}$ pore before and after irradiation are shown in Fig. $1 \mathrm{~b}$ and $\mathrm{c}$, respectively. The broad diffraction rings from an irradiated area establish the amorphous structure of the $\mathrm{Pd}_{80} \mathrm{Si}_{20}$ sample, as shown in the inset of Fig. 1a.

We observe the sculpting effect in different amorphous materials including $\mathrm{SiO}_{2}, \mathrm{SiN}_{\mathrm{x}}, \mathrm{Pd}_{80} \mathrm{Si}_{20}$, and $a-\mathrm{Si}$ but not in polycrystalline thin films of $\mathrm{Pt}$ or $\mathrm{Ag}$ deposited on $\mathrm{SiO}_{2}$ thin film substrates. This observation suggests that nanopore closure is limited to amorphous materials.

That amorphousness is a necessary condition for pore closing is supported by the results of irradiation of $c-\mathrm{Si}$ in a separate system capable of wide temperature excursions. For this experiment, irradiation was performed in an ultrahigh vacuum chamber (base pressure $=7 \times 10^{-11}$ torr at ambient $T$ ) with a 3 -cm RF ion source (Veeco, Fort Collins, $\mathrm{CO}$ ). Sample heating without fine temperature control to above $600{ }^{\circ} \mathrm{C}$, a temperature at which the surface remains crystalline under ion bombardment, was achieved with a pyrolytic boron nitride heater (GE Advanced Ceramics, Cleveland, $\mathrm{OH}$ ). The results are shown in Fig. 2: irradiation of $c$-Si pores at $T<100{ }^{\circ} \mathrm{C}$ resulted in substantial closure, whereas irradiation under otherwise identical conditions but at $T>600{ }^{\circ} \mathrm{C}$ resulted in undetectable closure.

Studies of crystalline Si following $\sim 1 \mathrm{keV}$ argon ion irradiation at room $T$ have established that a surface layer of thickness roughly (range + standard deviation) becomes amorphous. ${ }^{16}$ At high enough $T$, however, amorphous pockets created by the impinging ions are healed by thermally activated processes before a subsequent overlapping ion impingement arrives, and the crystalline structure is preserved. Amorphization and crystallization rates, and the direction of motion of the $a-c$ interface, critically depend on $T$ and ion mass, energy, and flux..$^{17-21}$ The dynamic $a-c$ transition temperature is that at which both rates are equal. We estimate this to be $\sim 540{ }^{\circ} \mathrm{C}$ for $\mathrm{Si}$ under the present irradiation conditions. Earlier studies at ambient $T$ have established that very low ion fluences $\left(\sim 10^{14} \mathrm{Ar}^{+} \mathrm{cm}^{-2}\right)$ are required to amorphize surfaces; ${ }^{22}$ thus, for our fluences $\left(\sim 10^{17} \mathrm{Ar}^{+} \mathrm{cm}^{-2}\right)$, below $100{ }^{\circ} \mathrm{C}$ we expect the $c$-Si pores to develop steady-state amorphous surface layers essentially as soon as irradiation begins. Furthermore, above $600{ }^{\circ} \mathrm{C}$, we expect the $c$-Si surfaces to remain crystalline during irradiation.

These observations are consistent with the anisotropic deformation mechanism that occurs in amorphous, but not crystalline, materials. ${ }^{23-26}$ Studies involving MeV irradiation of amorphous/crystalline metallic glass multilayers showed deformation only in amorphous regions. ${ }^{27,28}$ Fur- thermore, the thermal-spike mechanism of anisotropic heating from electronic stopping, flow, and quenching, ${ }^{12}$ is applicable only to amorphous materials. The experimental observations have been quantified in $1-\mathrm{D}^{24}$ and $3-\mathrm{D}^{26}$ using phenomenological stress- and strain-generation models, respectively. Subsequent results from low-energy ion irradiation experiments of free-standing nitride membranes using $30 \mathrm{keV} \mathrm{Ga}^{2+}$ ions have been shown ${ }^{29}$ to be consistent with the same constitutive relations as those developed to describe $\mathrm{MeV}$ irradiation effects, despite the dominance of nuclear stopping at low energy.

Recently, these ideas have been extended to develop the anisotropic deformation and viscous flow model that accounts reasonably well for pore closure in amorphous $\mathrm{Si}$ pores under $3 \mathrm{keV} \mathrm{Ar}^{+}$irradiation. ${ }^{13}$ In this model, compressive in-plane stress generated during ion irradiation by anisotropic deformation is relieved within a concurrentlyformed thin viscous surface layer exhibiting radiationenhanced fluidity; the resulting flow of the amorphous viscous layer into the pore causes pore closure. A competing model of adatom diffusion has also been shown to account for various features of the closure of silicon nitride pores under ion irradiation, including a flux pulsing effect and a temperature regime where pore closing rates are strongly $T$ dependent. ${ }^{1}$ On the one hand the adatom diffusion model does not predict the observation of pore closure in amorphous, but not crystalline, materials, because mobile species should - at least in principle - exist on both crystalline and amorphous surfaces. The observation of pore closure in amorphous, but not crystalline materials does not rule out the possibility of adatom diffusion being the dominant mechanism here: it is possible that the product of the adatom concentration and diffusivity on the crystalline surface is simply too small numerically compared to the amorphous surface, but we know of no reason to expect this to be a likely explanation. On the other hand, the flux-pulsing effect is not inconsistent with all plausible constitutive relations for ion-enhanced fluidity within the anisotropic deformation and viscous flow model: it has been argued ${ }^{13}$ to be inconsistent merely with the widely used constitutive relation in which the fluidity is strictly proportional to the instantaneous flux. If there is a unique mechanism at play in all the ion beam-stimulated nanopore closure experiments, its nature remains unsettled.

Fabrication of many electronic devices relies on the integration of insulators, metals, and semiconductors. An understanding of morphology evolution under ion irradiation and the ability to shrink features such as nanopores in these three essential materials classes in a controllable fashion could open an entirely different fabrication route to nanoscale devices. Multi-component devices fabricated at small but lithographically tractable scales could be further shrunk down to molecular dimensions via uniform ion irradiation. The integrity of the device would need to be maintained during shrinkage - this is no small challenge, but might be possible with self-organization or feedbackcontrol. In principle, because the nanopore closure rate for each material is a function of the ion species, energy, flux, and flux duty cycle, nanopores in three distinct materials should close at identical rates under identical irradiation conditions under a nonvanishing set of conditions.

In summary, ion irradiation induced closure of nanopores has been demonstrated in amorphous $\mathrm{SiN}, \mathrm{SiO}_{2}, \mathrm{Si}$, 
and $\mathrm{Pd}_{80} \mathrm{Si}_{20}$ nanopores and in crystalline $\mathrm{Si}$ nanopores that rapidly amorphize under ion irradiation, but not in polycrystalline Pt or Ag. This closing effect appears to be limited to materials that are or become amorphous, and is predicted by the mechanism of ion induced anisotropic deformation and viscous flow. At $T>600{ }^{\circ} \mathrm{C}$, above the amorphous-crystalline dynamic transition temperature where the c-Si surface is expected to be hot enough to remain crystalline during irradiation, we observed no significant pore closure, whereas under $100{ }^{\circ} \mathrm{C}$, where the surface rapidly amorphizes under irradiation, we observe significant closure. These findings open the opportunity for the integration of insulators, metals, and semiconductors into nanoelectronic devices at sub-lithographic length scales.

We acknowledge assistance from Slaven Garaj, Vidya Ramaswamy, Joost Vlassak, Cheng-Yen Wen and $\mathrm{Xi}$ Wang. One of us (M.J.A.) is grateful to U. Valbusa, F. Buatier de Mongeot and B. Torre for hospitality in a sabbatical-leave collaboration on preliminary experiments that failed to close nanopores in crystalline materials: finally we understand why. This work was supported by the U.S. Department of Energy through grant DE-FG02-06ER46335. D.P.H. acknowledges support from NDSEG and NSF Graduate fellowships. This work was performed in part at the Center for Nanoscale Systems at Harvard University member of the National Nanotechnology Infrastructure Network (NNIN), which is supported by the National Science Foundation under NSF award no. ECS-0335765.

*Corresponding author's email: maziz at harvard dot edu.

${ }^{1} \mathrm{~J}$. Li, D. Stein, C. McMullan, D. Branton, M.J. Aziz, and J. Golovchenko, Nature 412, 166 (2001).

${ }^{2}$ W.L. Chan and E. Chason, J. Appl. Phys. 101, 121301 (2007).

${ }^{3}$ W.L. Chan and E. Chason, Physical Review B 72, 165418 (2005).

${ }^{4}$ S. Facsko, T. Dekorsy, C. Koerdt, C. Trappe, H. Kurz, A. Vogt, and H.L. Hartnagel, Science 285, 1551 (1999).

${ }^{5}$ C.S. Madi, B. Davidovitch, H.B. George, S.A. Norris, M.P. Brenner, and M.J. Aziz, Phys. Rev. Lett. 101, 246102 (2008).

${ }^{6}$ J. Erlebacher, M. Aziz, E. Chason, M. Sinclair, and J. Floro, Physical Review Letters 82, 2330 (1999).

${ }^{7}$ B. Ziberi, F. Frost, and B. Rauschenbach, J. Vac. Sci. Technol. A 24, 1344 (2006).

${ }^{8}$ Q. Wei, J. Lian, W. Lu, and L. Wang, Phys. Rev. Lett. 100, 076103 (2008).

${ }^{9}$ C.C. Umbach, R.L. Headrick, and K.C. Chang, Phys. Rev. Lett.87, 246104 (2001).

${ }^{10}$ Q. Wei, J. Lian, S. Zhu, W. Li, K. Sun, and L. Wang, Chem. Phys. Lett. 452, 124 (2008).

${ }^{11}$ J. Li, M. Gershow, D. Stein, E. Brandin, and J.A. Golovchenko, Nature Materials 2, 611 (2003).

${ }^{12}$ T. van Dillen, A. Polman, P.R. Onck, and E. van der Giessen, Physical Review B 71, 024103 (2005).

${ }^{13}$ H.B. George, Y. Tang, X. Chen, J. Li, J.W. Hutchinson, J.A. Golovchenko, and M.J. Aziz (unpublished).

${ }^{14}$ D.M. Stein, C.J. McMullan, J.L. Li, and J.A. Golovchenko, Review of Scientific Instruments 75, 900 (2004)

${ }^{15}$ G.C. George and P.R.C. Stevens, Nuclear Instruments \& Methods 43, 278 (1966).

${ }^{16}$ C.S. Madi, unpublished

${ }^{17}$ K.A. Jackson, J. Mater. Res. 3, 1218 (1988).

${ }^{18}$ A. Battaglia, F. Priolo, and E. Rimini, Appl. Surf. Sci. 56-8, 577 (1992).

${ }^{19}$ L.A. Marques, L. Pelaz, M. Aboy, L. Enriquez, and J. Barbolla, Phys. Rev. Lett. 91, 135504 (2003).

${ }^{20}$ L. Pelaz, L.A. Marques, and J. Barbolla, J. Appl. Phys. 96, 5947 (2004).

${ }^{21}$ L. Pelaz, L.A. Marques, P. Lopez, L. Santos, M. Aboy, and J. Barbolla, Nuclear Instruments \& Methods in Physics Research B 241, 501 (2005).

${ }^{22}$ W. Bock, H. Gnaser, and H. Oechsner, Surface Science 282, 333 (1993).

${ }^{23}$ C.A. Volkert, Journal of Applied Physics 70, 3521 (1991).

${ }^{24}$ M.L. Brongersma, E. Snoeks, and A. Polman, Appl. Phys. Lett. 71, 1628 (1997).
${ }^{25}$ M.L. Brongersma, E. Snoeks, T. van Dillen, and A. Polman, J. Appl. Phys. 88, 59 (2000).

${ }^{26}$ K. Otani, X. Chen, J.W. Hutchinson, J.F. Chervinsky, and M.J. Aziz, J. Appl. Phys.100, 023535 (2006).

${ }^{27}$ F. Garrido, A. Benyagoub, A. Chamberod, J.C. Dran, A. Dunlop, S. Klaumunzer, and L. Thome, Physical Review B 52, 6273 (1995).

${ }^{28}$ F. Garrido, A. Benyagoub, A. Chamberod, J.C. Dran, A. Dunlop, S. Klaumunzer, and L. Thome, Nucl. Instrum. Methods Phys. Res. B 115, 430 (1996).

${ }^{29}$ Y.-R. Kim, P. Chen, M.J. Aziz, D. Branton, and J.J. Vlassak, J. Appl. Phys. 100, 104322 (2006).
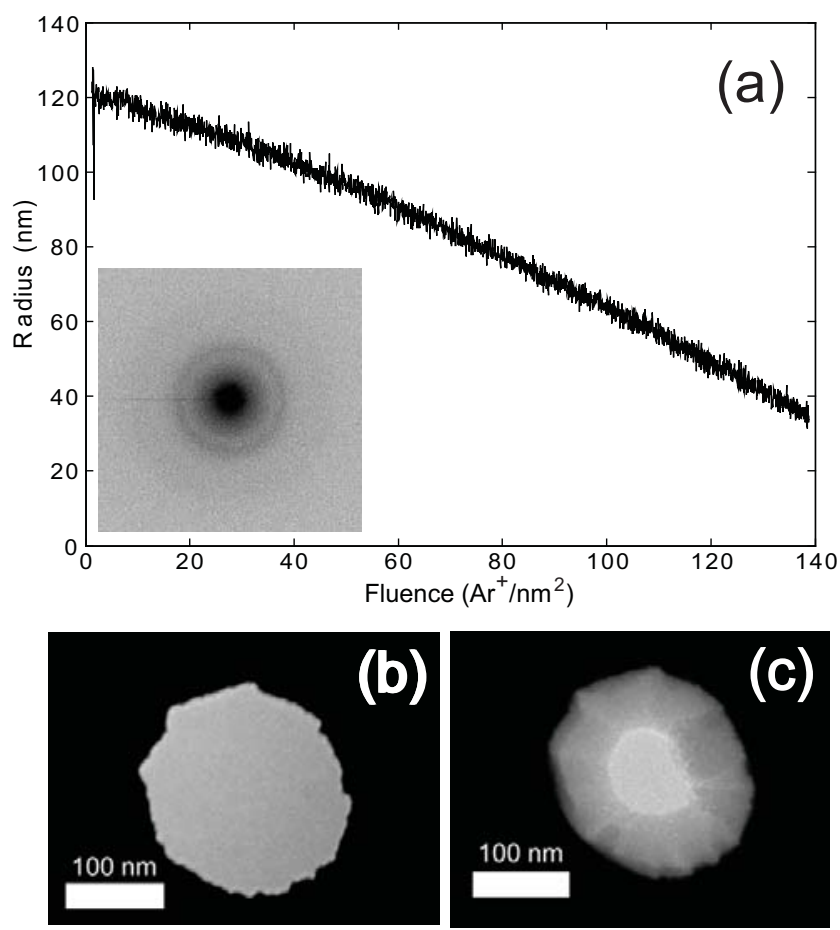

Fig. 1 (a) Real-time fluence dependence of a $\mathrm{Pd}_{80} \mathrm{Si}_{20}$ pore radius during ion sculpting with $3 \mathrm{keV} \mathrm{Ar}^{+}$at ambient temperature under ion flux of $0.053 \mathrm{Ar}^{+} \mathrm{nm}^{-2} \mathrm{~s}^{-1}$. The inset shows, in an inverted gray scale, a diffraction ring from the closed-in region of the sputtered sample confirming its amorphousness. (b) and (c) are TEM images of the pore in (a) before and after ion irradiation, respectively.
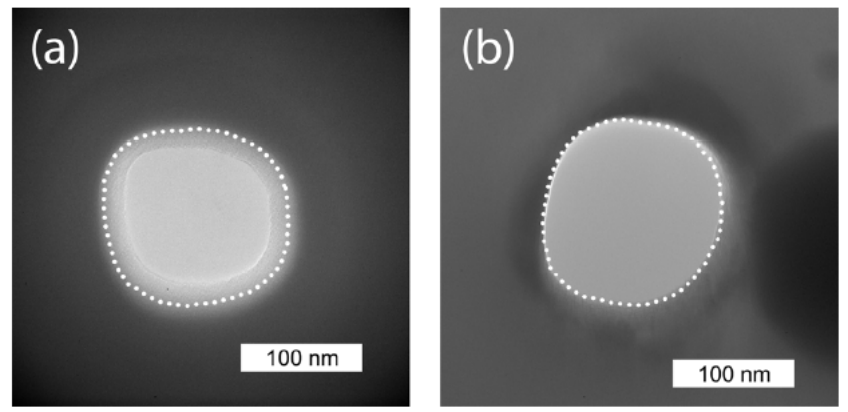

Fig. 2 TEM images of $c$-Si pores after $1.2 \mathrm{keV} \mathrm{Ar}^{+}$normal-incidence irradiation (a) $T<100{ }^{\circ} \mathrm{C}$, surface becomes amorphous; and (b) $T>$ $600{ }^{\circ} \mathrm{C}$, surface remains crystalline. Initial pore perimeters are indicated by the dotted white contours. Irradiation above the dynamic $a-c$ transition temperature preserves the crystallinity of the $c$-Si pore during irradiation and results in undetectable mass accretion at the pore edge. The ion flux was $22.5 \mathrm{Ar}^{+} \mathrm{nm}^{-2} \mathrm{~s}^{-1}$ with a total dose of (a) $1580 \mathrm{Ar}^{+} \mathrm{nm}^{-2}$ and (b) 3040 $\mathrm{Ar}^{+} \mathrm{nm}^{-2}$. A third pore (not shown) was closed completely with a total fluence of $5400 \mathrm{Ar}^{+} \mathrm{nm}^{-2}$ below the $a-c$ transition. The accreted material in (a) and in the completely closed pore was confirmed to be amorphous by TEM diffraction. 